\title{
Visualization of Dynamic Expression of Myocardial Sigma-1 Receptor After Myocardial Ischemia and Reperfusion Using Radioiodine-Labeled 2-[4-(2-iodophenyl)piperidino]cyclopentanol (OI5V) Imaging
}

\author{
Hiroshi Wakabayashi, MD, PhD; Junichi Taki, MD, PhD; Hiroshi Mori, MD; \\ Tomo Hiromasa, MD, PhD; Norihito Akatani, MD; Anri Inaki, MD, PhD; \\ Takashi Kozaka, PhD; Kazuhiro Shiba, PhD; \\ Kazuma Ogawa, PhD; Seigo Kinuya, MD, PhD
}

\begin{abstract}
Background: This study chronologically evaluated the expression of the intensity and distribution of the sigma-1 receptor $(\sigma 1 \mathrm{R})$ demonstrated by radiolabeled 2-[4-(2-iodophenyl)piperidino]cyclopentanol (OI5V) in a rat model of myocardial ischemia and reperfusion.

Methods and Results: The left coronary artery was occluded for $30 \mathrm{~min}$, followed by reperfusion. Dual-tracer autoradiography with ${ }^{125 I-O I 5 V ~ a n d ~} 99 \mathrm{mTC}-\mathrm{MIBI}$ was performed to assess the spatiotemporal changes in ${ }^{125} \mathrm{I}-\mathrm{OI} \mathrm{V}$ uptake $(\mathrm{n}=5-6)$. Significant and peaked

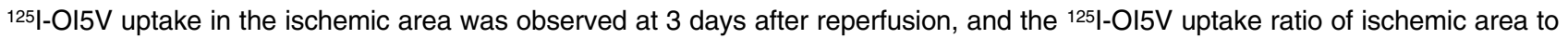
normally perfused left ventricular area decreased gradually from 3 to 28 days (mean value $\pm S D ; 0.90 \pm 0.12$ at 1 day, $1.89 \pm 0.19$ at 3 days, $1.52 \pm 0.17$ at 7 days, $1.34 \pm 0.13$ at 14 days, and $1.16 \pm 0.14$ at 28 days, respectively). Triple-tracer autoradiography with

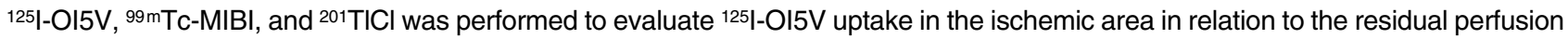
at 7 days $(n=4)$. The ${ }^{125} \mathrm{I}-\mathrm{OI} 5 \mathrm{~V}$ uptake ratio of the non-salvaged area was higher compared to that of the salvaged area in the ischemic area. ${ }^{123}$ I-OI5V and ${ }^{99 m}$ Tc-MIBI SPECT/CT was performed 3 days after reperfusion $(n=3)$, and the in vivo images showed clear uptake of ${ }^{123} \mathrm{I}-\mathrm{OI} 5 \mathrm{~V}$ in the perfusion defect area.
\end{abstract}

Conclusions: The present study confirmed the spatiotemporal expression pattern of $\sigma 1 \mathrm{R}$ expression. Non-invasive $\sigma 1 \mathrm{R}$ imaging with ${ }^{123}$ or or ${ }^{125} \mathrm{I}-\mathrm{OI} 5 \mathrm{~V}$ was feasible to monitor the expression of $\sigma 1 \mathrm{R}$ after myocardial ischemia and reperfusion.

Key Words: Memory imaging; Myocardial ischemia; OI5V; Sigma-1 receptor

$\mathbf{S}$ igma receptor was first recognized as an opioid receptor subtype in the $1970 \mathrm{~s},{ }^{1}$ and was later reclassified as a unique receptor due to its different properties. ${ }^{2}$ Two subtypes of sigma receptor (sigma-1 and -2 receptor) have been identified, ${ }^{3}$ and the sigma-1 receptor $(\sigma 1 \mathrm{R})$ was first cloned in 1996 from guinea pig liver. ${ }^{4}$ The $\sigma 1 \mathrm{R}$ primarily resides at the endoplasmic reticulum (ER) membrane associated with mitochondria (MAM) and is also translocated to the plasma membrane under stress. It acts as a chaperone that regulates protein folding / degradation, ER / oxidative stress, and cell survival. ${ }^{5}$ It is considered as a pluripotent modulator with resultant multiple functional manifestations in the living system. ${ }^{6}$ It has been intensively studied in the central nervous system thus far and

\section{Editorial p 2109}

has been implicated in many diseases, including schizophrenia, clinical depression, Alzheimer's disease, Parkinson's disease, cocaine addiction, stroke/ischemia, myocardial hypertrophy, and cancer. ${ }^{7,8}$

In the heart, $\sigma 1 \mathrm{R}$ is also expressed in cardiomyocytes as a chaperon and regulates the response to ER stress, modulates calcium handling, and affects the function of voltagegated-ion channels in abnormal states. ${ }^{5}$ The $\sigma 1 \mathrm{R}$ knockout mouse model demonstrated cardiac dysfunction with mitochondrial dysfunction, abnormal mitochondrial architecture, and adverse cardiac remodeling. ${ }^{9}$ The $\sigma 1 \mathrm{R}$ contributed to

Received April 6, 2021; revised manuscript received May 10, 2021; accepted May 13, 2021; J-STAGE Advance Publication released online June 26, 2021 Time for primary review: 23 days

Department of Nuclear Medicine, Kanazawa University Hospital, Kanazawa (H.W., J.T., H.M., T.H., N.A., A.I., S.K.); Division of Tracer Kinetics, Advanced Science Research Center (T.K., K.S.), Institute for Frontier Science Initiative (K.O.), Kanazawa University, Kanazawa, Japan

Mailing address: Hiroshi Wakabayashi, MD, PhD, Department of Nuclear Medicine, Kanazawa University Hospital, 13-1 Takara-machi, Kanazawa 920-8641, Japan. E-mail: wakabayashi@staff.kanazawa-u.ac.jp

All rights are reserved to the Japanese Circulation Society. For permissions, please e-mail: cj@j-circ.or.jp

ISSN-1346-9843 
A Dual-tracer autoradiography

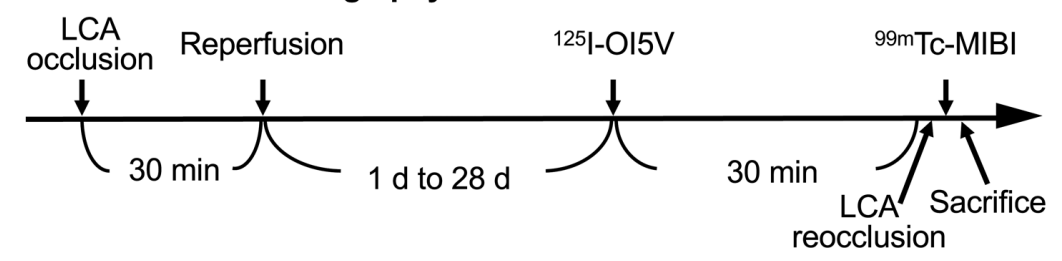

B Triple-tracer autoradiography

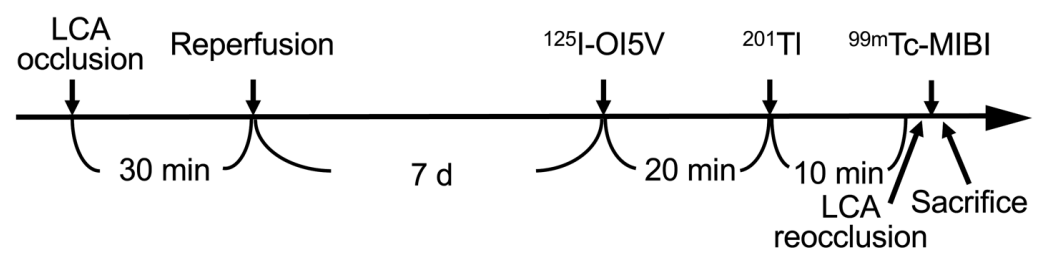

Figure 1. Autoradiography protocol for the rat model of 30 min ischemia and reperfusion. (A) The left coronary artery (LCA) was occluded for $30 \mathrm{~min}$, followed by reperfusion. At 1, 3, 7, 14, and 28 days after 30 min ischemia and reperfusion, ${ }^{125} \mathrm{I}-\mathrm{OI} 5 \mathrm{~V}$ was injected via a tail vein. Thirty min after the tracer

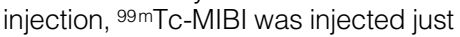
after reocclusion of the proximal portion of the LCA for delineation of the ischemic area in dual-tracer autoradiography. (B) In triple-tracer autoradiography, an additional $201 \mathrm{TI}$ was injected for the myocardial perfusion image 20 min after the ${ }^{125}$-OI5V injection. MIBI, hexakis 2-methoxyisobutyl isonitrile; OI5V, 2-[4-(2-iodophenyl) piperidino]cyclopentanol. understanding the pathophysiology of myocardial hypertrophy. In transverse aortic constriction (TAC) mice, $\sigma 1 \mathrm{R}$ is downregulated in cardiomyocytes following heart failure, ${ }^{10}$ however, the spatiotemporal expression patterns of $\sigma 1 \mathrm{R}$ after myocardial ischemia and reperfusion have not been explored.

A radiotracer ${ }^{125}$ I-2-[4-(2-iodophenyl)piperidino]cyclopentanol (OI5V), vesamicol analog with 5-membered ring structure, shows a high selective binding affinity for $\sigma 1 \mathrm{R}$. ${ }^{125} \mathrm{I}-\mathrm{OI} 5 \mathrm{~V}$ is a promising candidate for a $\sigma 1 \mathrm{R}$ imaging probe. ${ }^{11}$ The use of hybrid imaging devices such as singlephoton emission computed tomography (SPECT) with computed tomography $(\mathrm{CT})$ enables non-invasive imaging of $\sigma 1 \mathrm{R}$ distribution in preclinical and human subjects. Here, we evaluated the spatiotemporal changes in the intensity of the expression of $\sigma 1 \mathrm{R}$ demonstrated by OI5V radiolabeled with ${ }^{123} \mathrm{I}$ or ${ }^{125} \mathrm{I}$ in a rat model of ischemia and reperfusion.

\section{Methods}

\section{Animal Model of Acute Ischemia and Reperfusion}

All experimental animal protocols were approved by the Institute for Animal Studies of Kanazawa University (AP173846). All applicable Japanese and institutional guidelines for the care and use of animals were followed. Male Wistar rats, 8-9 weeks old, were anesthetized with intraperitoneal administration of secobarbital sodium, $40 \mathrm{mg} / \mathrm{kg}$, and were ventilated mechanically with room air. After left thoracotomy and exposure of the heart, a 7-0 polypropylene suture on a small curved needle was passed through the myocardium beneath the proximal portion of the left coronary artery (LCA), and both ends of the suture were passed through a small vinyl tube to make a snare. The suture material was pulled tightly against the vinyl tube to occlude the LCA in $30 \mathrm{~min}$. Myocardial ischemia was confirmed by ST-segment elevation on electrocardiography and by regional cyanosis of the myocardial surface. The snare was left loose on the surface of the heart for reocclusion of the LCA just before sacrificing the animals to identify the area at risk. For the sham operation group, only thread placement under LCA without ligation was conducted.

\section{Radiolabeling of $125 \mid-$ and $123|-0| 5 V$}

${ }^{125} \mathrm{I}-\mathrm{OI} 5 \mathrm{~V}$ was prepared from 2-[4-(2-trimethylstannylphenyl)piperidino]cyclopentanol (OT5V) $(50 \mu \mathrm{g} / 50 \mu \mathrm{L})$ and ${ }^{125} \mathrm{I}-\mathrm{NaI}(37 \mathrm{MBq})$ using the iodo-destannylation reaction under no-carrier-added conditions. ${ }^{11}$ After incubation for $10-20 \mathrm{~min}$ at room temperature, the prepared ${ }^{125} \mathrm{I}-\mathrm{OI} 5 \mathrm{~V}$ was purified with HPLC [reverse phase HPLC column (Zorbax-ODS RX-C18, $9.6 \times 250 \mathrm{~mm}$ ), $40^{\circ} \mathrm{C}, 2.0 \mathrm{~mL} / \mathrm{min}$ flow rate, 80:20:0.2 v/v/v acetonitrile/ $\mathrm{H}_{2} \mathrm{O} /$ monoethanolamine]. Radiolabeling of ${ }^{123}$ I-OI5V was performed using the same method as for ${ }^{125} \mathrm{I}-\mathrm{OI} 5 \mathrm{~V}$, except for use of ${ }^{123} \mathrm{I}-$ $\mathrm{NaI}(111 \mathrm{MBq})$ instead of ${ }^{125} \mathrm{I}-\mathrm{NaI}(37 \mathrm{MBq})$.

The radiochemical yield of ${ }^{123} \mathrm{I}-$ and ${ }^{125} \mathrm{I}-\mathrm{OI} 5 \mathrm{~V}$ was $70-80 \%$. After purification, ${ }^{123} \mathrm{I}-$ and ${ }^{125} \mathrm{I}-\mathrm{OI} 5 \mathrm{~V}$ showed a radiochemical purity of over $99 \%$.

\section{Dual-Tracer Autoradiography}

At $1,3,7,14$, and 28 days after $30 \mathrm{~min}$ ischemia and reperfusion, ${ }^{125} \mathrm{I}-\mathrm{OI} 5 \mathrm{~V}(1.5 \mathrm{MBq})$ was injected via a tail vein $(n=5$ for 1 day and $n=6$ for $3,7,14$, and 28 days). After $30 \mathrm{~min}$ of the tracer injection, $185 \mathrm{MBq}$ of $99 \mathrm{~m}$ Tc-hexakis 2-methoxyisobutyl isonitrile (MIBI) was injected just after the reocclusion of the LCA for the delineation of ischemic area (area at risk) (Figure 1A). One minute later, the rat was euthanized, and the heart was removed for analysis. The heart was rinsed in saline, embedded in methyl cellulose, and cooled in a freezer. Serial short-axis heart sections of $20 \mu \mathrm{m}$ thickness were obtained using a cryostat to create a series of rings for autoradiography. The first autoradiographic exposure on an imaging plate (BAS-MS; Fuji Film) was performed for $15-20 \mathrm{~min}$ to visualize $99 \mathrm{mTc}-$ MIBI distribution 1-2 $\mathrm{h}$ after sacrifice (area at risk). Three days later ( 12 half-lives of ${ }^{99} \mathrm{mTc}$ ), the second exposure was made for 4 days to image ${ }^{125}$ I-OI5V distribution.

As a blocking study, an excess of an unlabeled sigma ligand, (+/-)-pentazocine $(10 \mu \mathrm{mol})$, was injected into the rat $20 \mathrm{~min}$ before the ${ }^{125} \mathrm{I}-\mathrm{OI} 5 \mathrm{~V}$ injection at 3 days after ischemia and reperfusion $(n=3)$.

\section{Triple-Tracer Autoradiography}

To compare the distribution of perfusion tracer [ ${ }^{201} \mathrm{Tl}$ chrolide

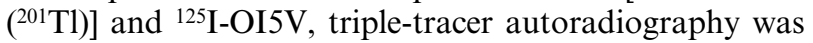
performed using the rat model of 7 days after ischemia and 

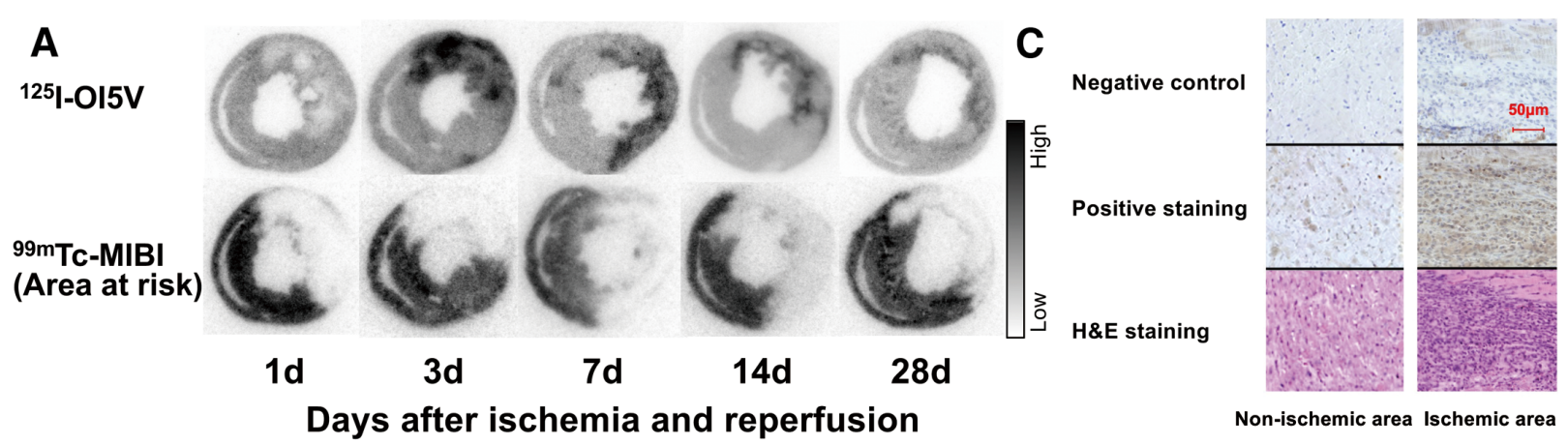

B
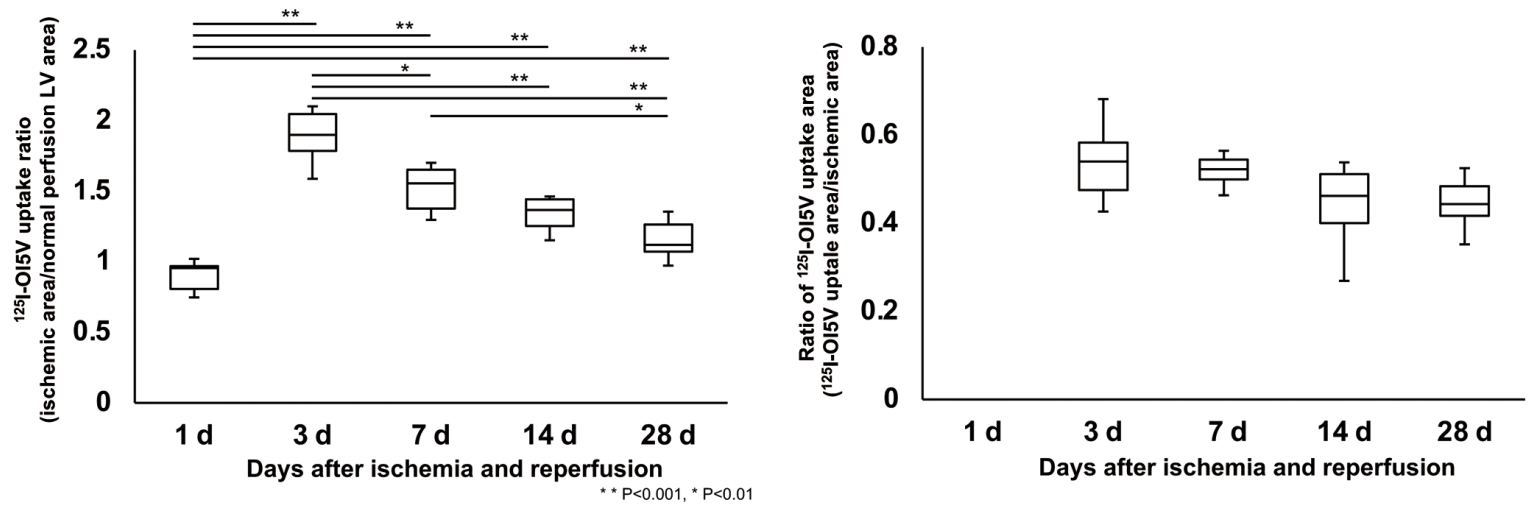

Figure 2. (A) Corresponding dual-tracer autoradiographic short-axis images in rats after ischemia and reperfusion ( ${ }^{125}$-OI5V and $99 \mathrm{mTC}-\mathrm{MIBI}$ ). (B) Time course of ${ }^{125}$ I-OI5V uptake ratio of ischemic area to remote uptake after coronary occlusion and reperfusion. $99 \mathrm{mTc}-\mathrm{MIBI}$ images demonstrate the ischemic area because the tracer was injected during coronary reocclusion before sacrifice. Box and whisker plot show the range from $25 \%$ to $75 \%$. The median value is indicated with a horizonal bar, and the whiskers indicate the upper and lower limits. Intense ${ }^{125}$ I-OI5V uptake was observed in the ischemic area at 3 days after ischemia and reperfusion. The increase of tracer signal in the ischemic area peaked at 3 days, followed by a gradual reduction of uptake until the 28th day. The ratio of ${ }^{125} \mathrm{I}-\mathrm{OI} 5 \mathrm{~V}$ uptake area in the ischemic area did not change from 3 to 28 days. (C) Immunohistochemical staining (brown) showed an increased Sigma-1 receptor in the ischemic area at 3 days after ischemia and reperfusion. MIBI, hexakis 2-methoxyisobutyl isonitrile; OI5V, 2-[4-(2-iodophenyl)piperidino]cyclopentanol.

reperfusion. After $20 \mathrm{~min}$ of ${ }^{125} \mathrm{I}-\mathrm{OI} 5 \mathrm{~V}(1.5 \mathrm{MBq})$ injection $(\mathrm{n}=4),{ }^{201} \mathrm{Tl}(10 \mathrm{MBq})$ was injected (Figure 1B). Ten minutes later, $185 \mathrm{MBq}$ of $99 \mathrm{~m}$ Tc-MIBI was injected just after reocclusion of the proximal portion of the LCA for delineation of the ischemic area. One minute later, the rat was euthanized and the heart was removed for analysis. The heart was rinsed in saline, embedded in methyl cellulose, and cooled in a freezer. Serial short-axis heart sections of $20 \mu \mathrm{m}$ thickness were obtained using a cryostat to create a series of rings for autoradiography. The first autoradiographic exposure on an imaging plate was performed for 15-20 min to visualize ${ }^{99 \mathrm{~m}} \mathrm{Tc}-\mathrm{MIBI}$ distribution $1-2 \mathrm{~h}$ after sacrifice. Three days later ( 12 half-lives of ${ }^{99} \mathrm{mTc}$ ), the second exposure was made for 5-6h to image the myocardial perfusion expressed by ${ }^{201} \mathrm{Tl}$ distribution. One month (10 half-lives of ${ }^{201} \mathrm{Tl}$ ) or more later, the third exposure was made for 7 days to image the $\sigma 1 \mathrm{R}$ expression by ${ }^{125} \mathrm{I}-\mathrm{OI} 5 \mathrm{~V}$ distribution.

\section{Data Analysis}

${ }^{125} \mathrm{I}-\mathrm{OI} 5 \mathrm{~V}$ accumulation was evaluated in 3 myocardial slices (20- $\mu \mathrm{m}$ thickness) at the mid-ventricular level spaced 1-mm apart from one another. The distribution of the tracers was determined by analysis of the digitized autoradiographs. The photostimulated luminescence in each pixel $(50 \times 50 \mu \mathrm{m})$ was determined using a bioimaging analyzer (BAS-5000; Fuji Film).

For quantitative analysis, the uptake values for each region of interest (ROI) were expressed as the backgroundcorrected photostimulated luminescence per unit area $\left(0.25 \mathrm{~mm}^{2}\right)$. A background ROI was set adjacent to the left ventricle. Ischemic and normally perfused areas were

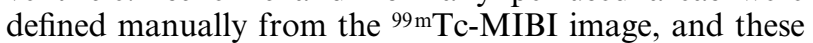
ROIs were applied to the ${ }^{125} \mathrm{I}-\mathrm{OI} 5 \mathrm{~V}$ images to evaluate the uptake of ${ }^{125} \mathrm{I}-\mathrm{OI} 5 \mathrm{~V}$. The ${ }^{125} \mathrm{I}-\mathrm{OI} 5 \mathrm{~V}$ uptake ratio was calculated by dividing the uptake value of an ischemic area by that of a normally perfused area in the dual-autoradiography.

Area of preserved perfusion area (salvaged area) and decreased perfusion area (non-salvaged area) in the ischemic area were defined from the ${ }^{201} \mathrm{Tl}$ image. The salvaged and non-salvaged areas were defined as $\geq 60 \%$ uptake and $<60 \%$ uptake of a normally perfused area, respectively. ${ }^{12}$ These ROIs were applied to the ${ }^{125} \mathrm{I}-\mathrm{OI} 5 \mathrm{~V}$ images to evaluate the uptake of ${ }^{125}$ I-OI5V. The ${ }^{125}$ I-OI5V uptake ratio was calculated by dividing the uptake values of a non-salvaged area and salvage area by that of a normally perfused area. 


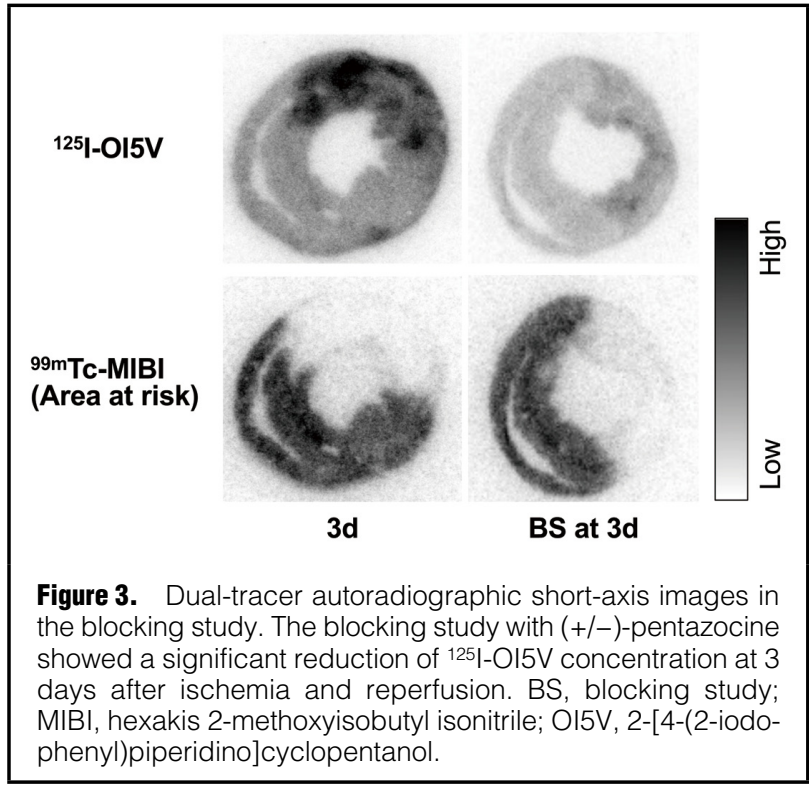

\section{Immunohistochemical Staining}

Tissues were fixed in $4 \%$ buffered formalin and processed for paraffin embedding. Left ventricular short axial sections (5- $\mu \mathrm{m}$ thickness) were cut from the middle area. Short-axis heart sections were stained with anti- $\sigma 1 \mathrm{R}$ antibody (ab151288, abcam) using a direct immunoperoxidase technique (ab64261, abcam). Counterstaining was performed to visualize nuclei and tissue architecture with hematoxylin. Hematoxylin-eosin staining was performed by using standard procedures. The site and distribution of the expression of $\sigma 1 \mathrm{R}$ were examined by immunofluorescence microscopy $(400 \times)$.

\section{Post-Mortem Tissue Counting}

In the model of $30 \mathrm{~min}$ ischemia and reperfusion and shamoperated rats, ${ }^{125} \mathrm{I}-\mathrm{OI} 5 \mathrm{~V}(0.25 \mathrm{MBq})$ was injected through a tail vein catheter at 3 days after $30 \mathrm{~min}$ ischemia and reperfusion ( $\mathrm{n}=5$ for each group). The rats were euthanized at $30 \mathrm{~min}$ after tracer administration. Then, organs of interest (blood, lung, heart, liver, kidney, spleen, pancreas, stomach, intestine, muscle, bone) were collected, weighed, and counted for radioactivity in an automated gamma counter. For the ischemia and reperfusion rats, the heart was divided into ischemic and non-ischemic areas. In the sham-operated rats, the heart was arbitrarily divided into ischemic (LCA territory) and non-ischemic area (lower septal area). Tissue radioactivity concentrations were measured and expressed as injected dose per gram $(\% \mathrm{ID} / \mathrm{g})$ of each organ sample.

\section{In Vivo SPECT/CT Imaging}

Three rats were imaged using a small animal SPECT system (versatile emission computed tomography, VECTor) equipped with a general-purpose rat collimator (MI-labs, The Netherlands). At 3 days after ischemia and reperfusion, the rats received $74 \mathrm{MBq}$ of ${ }^{123}$ I-OI5V via a tail vein $30 \mathrm{~min}$ before SPECT. The animals were scanned for $10 \mathrm{~min}$ under $1-2 \%$ isoflurane anesthesia. Then, $185 \mathrm{MBq}$ of $99 \mathrm{~m}$ Tc-MIBI was injected via a tail vein $60 \mathrm{~min}$ before SPECT, in order to evaluate the decreased perfusion area. Again, 10 min gated SPECT imaging was performed.

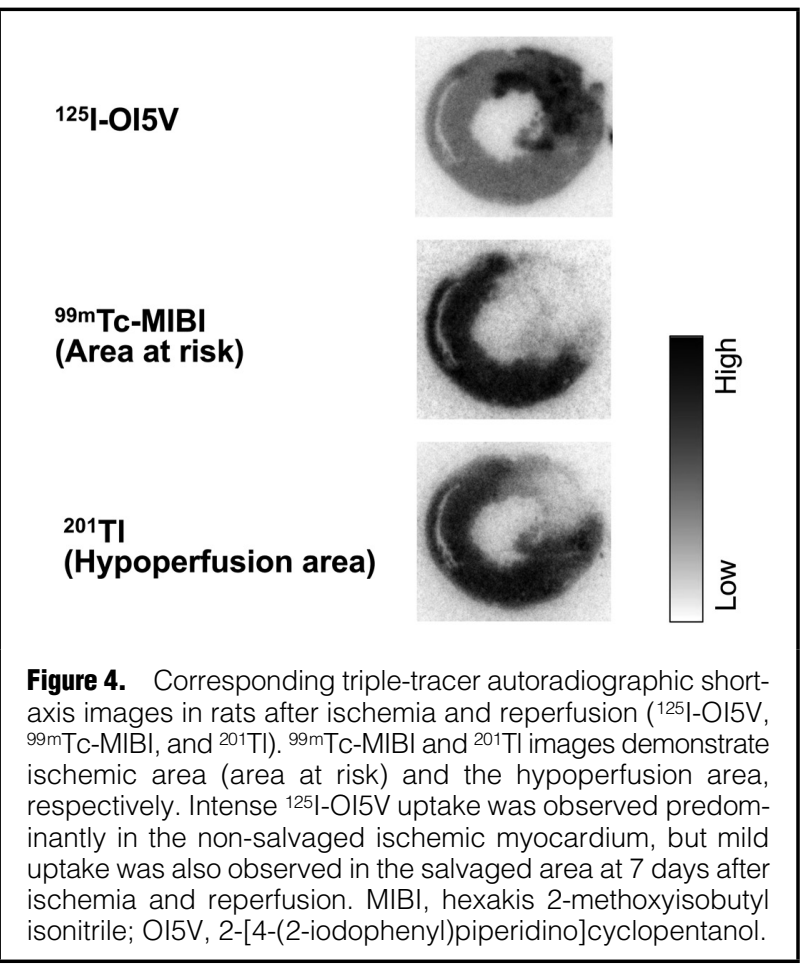

\section{SPECT Data Reconstruction}

Data were acquired in list mode and photopeak windows were set after the acquisition. Triple energy window scatter correction was employed (a 20\% photopeak window centered at 159 and $140 \mathrm{keV}$ for ${ }^{123} \mathrm{I}$ and ${ }^{99 \mathrm{~m}} \mathrm{Tc}$, respectively, abutting the upper and lower scatter windows $4.5 \%$ in width).

Data were reconstructed using pixel-based order-subsets expectation maximization, without correction for attenuation on CT, in 13 subsets and 6 iterations. ${ }^{13,14}$ The voxel size was $0.8 \times 0.8 \times 0.8 \mathrm{~mm}$.

The obtained SPECT images were analyzed using an image-processing application (AMIDE Imaging software, version 1.0.1). ${ }^{15}$ Three-dimensional regions of interest were manually drawn over the area of decreased perfusion and normally perfused area in serial 15 slices. We set the ROI at the mid-ventricular level to avoid the physiological liver uptake of ${ }^{123} \mathrm{I}-\mathrm{OI} 5 \mathrm{~V}$. The mean concentration of radioactivity within the regions of interest was calculated. The count ratio was calculated as the ratio of the average counts per voxel in the area of decreased perfusion divided by that in the normally perfused area.

\section{Statistical Analysis}

For all statistical analyses, we used a statistical software package (JMP ${ }^{\circledR}$ SAS Institute, Inc., Cary, NC, USA.). All results were expressed as the mean value \pm standard deviation (SD). Group comparisons were performed using analysis of variance. Statistical significance was determined using analysis of variance (ANOVA) and Tukey's honestly significant difference (HSD) test for comparing the ${ }^{125} \mathrm{I}-\mathrm{OI} 5 \mathrm{~V}$ uptake ratio and the ratio of ${ }^{125}$ I-OI5V uptake area in the ischemic area in the dual-tracer autoradiography. The paired-t analysis was performed to compare the ${ }^{125} \mathrm{I}-\mathrm{OI} 5 \mathrm{~V}$ uptake ratio in the area of non-salvage and the salvage area in the triple-tracer autoradiography. The t-test was performed to compare the tracer signals between the model 


\begin{tabular}{|c|c|c|c|}
\hline \multirow[b]{2}{*}{ Organ } & \multicolumn{2}{|c|}{ Uptake $(\% \mathrm{ID} / \mathrm{g})^{\dagger}$} & \multirow[b]{2}{*}{$P$ value } \\
\hline & Sham-operated rats & $\begin{array}{l}\text { Rats with ischemia } \\
\text { and reperfusion }\end{array}$ & \\
\hline Blood & $0.08 \pm 0.01$ & $0.07 \pm 0.01$ & NS \\
\hline Lung & $3.53 \pm 0.80$ & $3.74 \pm 0.80$ & NS \\
\hline \multicolumn{4}{|l|}{ Heart } \\
\hline Non-ischemic area & $0.53 \pm 0.06$ & $0.62 \pm 0.03$ & NS \\
\hline Ischemic area (operated area) & $0.53 \pm 0.03$ & $1.76 \pm 0.37$ & $<0.0001$ \\
\hline Liver & $1.38 \pm 0.15$ & $1.18 \pm 0.15$ & NS \\
\hline Kidney & $1.96 \pm 0.14$ & $2.10 \pm 0.14$ & NS \\
\hline Spleen & $1.62 \pm 0.11$ & $1.67 \pm 0.11$ & NS \\
\hline Pancreas & $2.66 \pm 0.39$ & $2.44 \pm 0.32$ & NS \\
\hline Stomach & $1.03 \pm 0.25$ & $0.67 \pm 0.25$ & NS \\
\hline Intestine & $2.18 \pm 0.66$ & $2.02 \pm 0.66$ & NS \\
\hline Muscle & $0.10 \pm 0.01$ & $0.12 \pm 0.01$ & 0.03 \\
\hline Bone & $0.33 \pm 0.01$ & $0.36 \pm 0.01$ & NS \\
\hline
\end{tabular}

tUptake values are presented as mean percentage of the injection dose per gram of tissue $(\% \mathrm{ID} / \mathrm{g}) \pm$ standard deviation. NS, not significant.

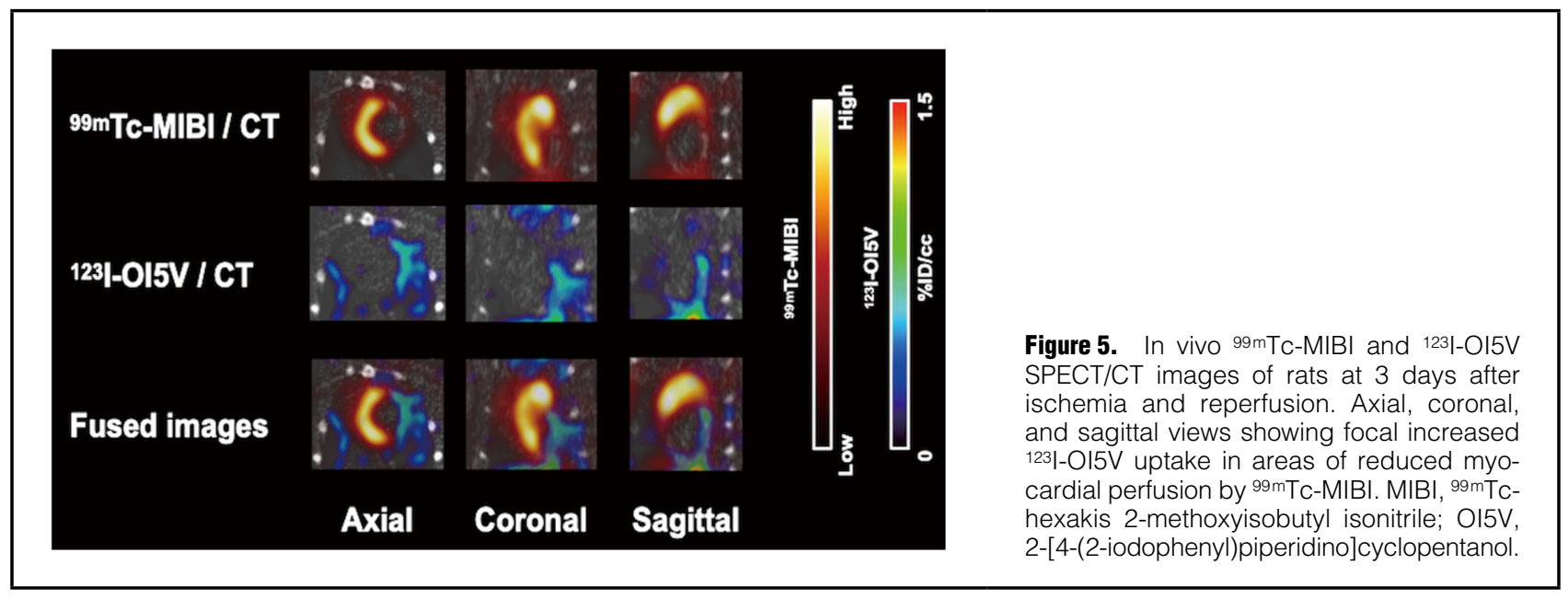

and sham-operated rats in the post mortem tissue counting study and the mean ${ }^{123}$ I-OI5V uptake ratio of the decreased perfusion area to the preserved perfusion area in the in vivo SPECT imaging. A value of $\mathrm{P}<0.05$ was considered statistically significant.

\section{Results}

Dual-Tracer Autoradiography

Autoradiography showed homogeneous ${ }^{125}$ I-OI5V uptake in the myocardium in healthy rat hearts $(n=2)$. Perfusion defects and focal ${ }^{125} \mathrm{I}-\mathrm{OI} 5 \mathrm{~V}$ uptake were not observed in the sham-operated rats $(n=4)$.

The area of increased ${ }^{125} \mathrm{I}-\mathrm{OI} 5 \mathrm{~V}$ uptake was localized in the area of ischemia (area at risk), as shown by ${ }^{99 \mathrm{mTc}-}$ MIBI uptake defect. No significant elevation of ${ }^{125} \mathrm{I}-\mathrm{OI} 5 \mathrm{~V}$ uptake was found in the non-ischemic area, identified by $99 \mathrm{mTc}-\mathrm{MIBI}$. At 1 day after ischemia and reperfusion, a ${ }^{125} \mathrm{I}-\mathrm{OI} 5 \mathrm{~V}$ image demonstrated reduced tracer activity in the area at risk compared to the normally perfused area; however, ${ }^{125} \mathrm{I}-\mathrm{OI} 5 \mathrm{~V}$ uptake increased significantly and peaked at 3 days after ischemia and reperfusion followed by gradual reduction until 28 days (Figure 2A). The ${ }^{125} \mathrm{I}-\mathrm{OI} 5 \mathrm{~V}$ uptake ratios of ischemic area to normal perfusion $L V$ area were $0.90 \pm 0.12$ at 1 day, $1.89 \pm 0.19$ at 3 days, $1.52 \pm 0.17$ at 7 days, $1.34 \pm 0.13$ at 14 days, and $1.16 \pm 0.14$ at 28 days (Figure 2B). The ratio of ${ }^{125}$ I-OI5V uptake area to the ischemic area was $0 \pm 0$ at 1 day, $0.54 \pm 0.09$ at 3 days, $0.52 \pm 0.04$ at 7 days, $0.44 \pm 0.10$ at 14 days, and $0.44 \pm 0.06$ at 28 days. The ratio of ${ }^{125}$ I-OI5V uptake area in the ischemic area did not change from 3 to 28 days. The blocking study with (+/-)-pentazocine showed a marked reduction of ${ }^{125} \mathrm{I}-\mathrm{OI} 5 \mathrm{~V}$ uptake at 3 days from $1.89 \pm 0.20$ to $1.13 \pm 0.18$ $(\mathrm{P}<0.05$, Figure 3).

\section{Immunohistochemical Analysis}

Significant immunohistochemical staining showed an increased $\sigma 1 \mathrm{R}$ on the myocardium in the ischemic area (area at risk) at 3 days after ischemia and reperfusion (Figure 2C).

\section{Triple-Tracer Autoradiography}

125I-OI5V uptake was observed in both the salvaged and 
non-salvaged areas of the ischemic area at 7 days after ischemia and reperfusion (Figure 4), whereas no significant regional elevation of ${ }^{125}$ I-OI5V uptake was found in the non-ischemic area. The salvaged area was observed in $67 \pm 13 \%$ of the ischemic area (area at risk). The ${ }^{125} \mathrm{I}-\mathrm{OI} 5 \mathrm{~V}$ uptake ratio of the non-salvaged area was higher compared to that of the salvaged area $(2.11 \pm 0.30$ vs. $1.46 \pm 0.14$, $\mathrm{P}<0.01)$.

\section{Systemic ${ }^{125 \mid-015 V ~ D i s t r i b u t i o n ~}$}

In vivo biodistribution was evaluated at $30 \mathrm{~min}$ after ${ }^{125} \mathrm{I}-\mathrm{OI} 5 \mathrm{~V}$ administration. The lung, kidney, pancreas, and intestine exhibited high tracer concentration, and tracer uptake in the blood remained very low. Tracer uptake in the cardiac ischemic area was higher in rats with an ischemia and reperfusion model compared with that of shamoperated rats. In the non-ischemic area, tracer uptake tended to be higher after the ischemia and reperfusion. The results of the post mortem tissue counting study are summarized in Table.

\section{In Vivo SPECT/CT Imaging}

Focally increased ${ }^{123} \mathrm{I}-\mathrm{OI} 5 \mathrm{~V}$ uptake in the myocardium was clearly observed in the hypoperfused area showing reduced $99 \mathrm{~m}$ Tc-MIBI uptake at 3 days after ischemia and reperfusion (Figure 5). The mean count ratio of the decreased perfusion area to the preserved perfusion area was $2.0 \pm 0.2$ at 3 days after ischemia and reperfusion $(n=3)$.

\section{Discussion}

The present study demonstrated the feasibility of imaging with OI5V targeted at the $\sigma 1 \mathrm{R}$, and documented, for the first time, spatiotemporal profiling of $\sigma 1 \mathrm{R}$ expression after myocardial ischemia and reperfusion. We surmise that in the model of ischemia and reperfusion, ischemia is the major factor determining the degree of $\sigma 1 \mathrm{R}$ expression, in that the ${ }^{125} \mathrm{I}-\mathrm{OI} 5 \mathrm{~V}$ uptake was higher in the non-salvaged area than the salvaged area. Furthermore, ${ }^{125} \mathrm{I}-\mathrm{OI} 5 \mathrm{~V}$ imaging revealed that the $\sigma 1 \mathrm{R}$ expression changes dynamically after ischemia and reperfusion.

$\sigma 1 \mathrm{R}$ has been found in cardiomyocytes, where it was documented to play a role in contractility and beating frequency. ${ }^{16,17} \sigma 1 \mathrm{R}$ ligands, agonists or antagonists have been applied to observe the downstream effects to elucidate the mechanism of its action in the heart. $\sigma 1 \mathrm{Rs}$ as chaperones have been shown to be involved in ER stress, calcium handling, voltage-gated ion channeling, cellular toxicity/ apoptosis, and hypertrophy., ${ }^{\mathbf{5} 18}$ Here, the modulation of the $\sigma 1 \mathrm{R}$ signal with ligands was implicated in cardioprotection. However, the possible involvement of $\sigma 1 \mathrm{R}$ expression in the pathophysiological process has not yet been examined in ischemic heart disease, though ischemia and reperfusion injury trigger calcium imbalance, ER stress, and apoptosis. ${ }^{19}$ The current study confirms that $\sigma 1 \mathrm{R}$ overexpression occurs shortly after ischemia and reperfusion.

$\sigma 1 \mathrm{R}$ has been found to act as a pluripotent modulator in various conditions, including ischemia. ${ }^{18}$ Our imaging study is in line with prior studies showing the presence of $\sigma 1 \mathrm{R}$ under ischemia in the brain of mice with permanent middle cerebral artery occlusion, ${ }^{\mathbf{2 0}}$ in which $\sigma 1 \mathrm{R}$ expression increased in the peri-infarcted area at 1 week after infarction. However, its chronological changes and distribution in the brain are unknown. We here clarified the spatiotemporal $\sigma 1 \mathrm{R}$ expression in the damaged heart after ischemia and reperfusion.

In the autoradiographic study, significant $\sigma 1 \mathrm{R}$ expression was observed in the myocardium within the ischemic area, with the expression peaking at 3 days, followed by a gradual reduction to 28 days. At 3 days after ischemia and reperfusion, we also confirmed the presence of $\sigma 1 \mathrm{R}$ in the ischemic area by immunostaining, a high tracer signal in the ischemic area by postmortem tissue counting, and the significant reduction of the tracer signal by a blocking study. $\sigma 1 \mathrm{R}$ is an ER protein that primarily resides specifically in the mitochondria-associated ER membrane; however, it can be translocated to the plasma membrane, mitochondria, nucleus envelope and cytosol, and functions as the chaperone during various increasing cellular stresses.. $\mathbf{5 , 6 , 1 7}$ Based on the presence of $\sigma 1 \mathrm{R}$ under stress, the ${ }^{125} \mathrm{I}-\mathrm{OI} 5 \mathrm{~V}$ uptake demonstrated by autoradiography may correspond to the upregulated $\sigma 1 \mathrm{R}$ in the cardiomyocytes after ischemia and reperfusion.

The current study demonstrated the inhomogeneous expression of ${ }^{125} \mathrm{I}-\mathrm{OI} 5 \mathrm{~V}$ in the ischemic area regardless of the salvage status. The triple autoradiography showed higher ${ }^{125} \mathrm{I}-\mathrm{OI} 5 \mathrm{~V}$ uptake in the non-salvage area compared with the salvaged area in the ischemic region. The discordant ${ }^{125} \mathrm{I}-\mathrm{OI} 5 \mathrm{~V}$ uptake in the decreased perfusion area may reflect the presence of residual myocardium jeopardized by more severe ischemia. In response to severe ischemia, cardiomyocytes increase the expression of various chaperones and activities as a salvage mechanism to manage emergency conditions. ${ }^{21}$ If a more intense expression of $\sigma 1 \mathrm{R}$ reflects more severe ischemic damage in viable myocardium, $\sigma 1 \mathrm{R}$ imaging could embody the concept of the stress imaging, reflecting prior damage or current stress.

ER stress plays an essential role in developing and progressing cardiovascular disease..$^{22,23} \mathrm{We}$ speculated that $\sigma 1 \mathrm{R}$ imaging also might be beneficial in non-ischemic heart disease such as myocardial hypertrophy due to TAC; the $\sigma 1 \mathrm{R}$ was gradually downregulated along with ventricular dysfunction. ${ }^{10,18,24}$ In such a condition, the tracer uptake in the heart might decrease. For the evaluation of $\sigma 1 \mathrm{R}$ downregulation, absolute quantification of the tracer uptake should be important.

The OI5V was radiolabeled with radioiodine so that the radioactivity would reveal the in vivo dynamics of $\sigma 1 \mathrm{R}$ expression. The average ${ }^{123} \mathrm{I}-\mathrm{OI} 5 \mathrm{~V}$ count ratio in in vivo SPECT/CT is similar to the average ratio of the ischemic area to normal LV area obtained from the ${ }^{125} \mathrm{I}-\mathrm{OI} 5 \mathrm{~V}$ autoradiography study. For future clinical application as a SPECT, ${ }^{123}$ I-OI5V would be beneficial to monitor and clarify how $\sigma 1 \mathrm{R}$ is involved pathophysiologically in the period of post myocardial infarction induced by ischemia and reperfusion. However, in the interpretation of inferior myocardial uptake, we must take into consideration the effect of relatively high liver uptake.

\section{Conclusions}

The present study demonstrated the feasibility of targeted imaging for serial assessment of regional expression of $\sigma 1 \mathrm{R}$ after myocardial ischemia and reperfusion. It also demonstrated the expression pattern in relation to myocardium perfusion status after $30 \mathrm{~min}$ of ischemia and reperfusion. The data from this study implied that, by allowing visualization of $\sigma 1 \mathrm{R}$ expression, radiolabeled OI5V imaging may be a non-invasive way to monitor myocardial injury and its ER stress after ischemia and reperfusion. 


\section{Sources of Funding}

This work has been supported by the Japan Society for the Promotion of Science (JSPS) KAKENHI, Grant Number JP20K08047.

\section{Disclosures}

The authors declare that they have no conflict of interests.

\section{References}

1. Martin WR, Eades CG, Thompson JA, Huppler RE, Gilbert PE. The effects of morphine- and nalorphine- like drugs in the nondependent and morphine-dependent chronic spinal dog. J Pharmacol Exp Ther 1976; 197: 517-532.

2. Quirion R, Bowen WD, Itzhak Y, Junien JL, Musacchio JM, Rothman RB, et al. A proposal for the classification of sigma binding sites. Trends Pharmacol Sci 1992; 13: 85-86.

3. Hellewell SB, Bruce A, Feinstein G, Orringer J, Williams W, Bowen WD. Rat liver and kidney contain high densities of sigma 1 and sigma 2 receptors: Characterization by ligand binding and photoaffinity labeling. Eur J Pharmacol 1994; 268: 9-18.

4. Hanner M, Moebius FF, Flandorfer A, Knaus HG, Striessnig J, Kempner E, et al. Purification, molecular cloning, and expression of the mammalian sigma1-binding site. Proc Natl Acad Sci USA 1996; 93: 8072-8077.

5. Stracina T, Novakova M. Cardiac sigma receptors: An update. Physiol Res 2018; 67: S561-S576.

6. Su TP, Su TC, Nakamura Y, Tsai SY. The Sigma-1 receptor as a pluripotent modulator in living systems. Trends Pharmacol Sci 2016; 37: 262-278.

7. Penke B, Fulop L, Szucs M, Frecska E. The role of Sigma-1 receptor, an intracellular chaperone in neurodegenerative diseases. Curr Neuropharmacol 2018; 16: 97-116.

8. Vilner BJ, John CS, Bowen WD. Sigma-1 and sigma-2 receptors are expressed in a wide variety of human and rodent tumor cell lines. Cancer Res 1995; 55: 408-413.

9. Abdullah CS, Alam S, Aishwarya R, Miriyala S, Panchatcharam M, Bhuiyan MAN, et al. Cardiac dysfunction in the Sigma 1 receptor knockout mouse associated with impaired mitochondrial dynamics and bioenergetics. J Am Heart Assoc 2018; 7: e009775.

10. Tagashira H, Bhuiyan S, Shioda N, Hasegawa H, Kanai H, Fukunaga K. Sigmal-receptor stimulation with fluvoxamine ameliorates transverse aortic constriction-induced myocardial hypertrophy and dysfunction in mice. Am J Physiol Heart Circ Physiol 2010; 299: H1535-H1545.

11. Shigeno T, Kozaka T, Kitamura Y, Ogawa K, Taki J, Kinuya S, et al. In vitro and in vivo evaluation of [(125/123)I]-2-[4-(2-iodo-
phenyl)piperidino]cyclopentanol([(125/123)I]-OI5V) as a potential sigma-1 receptor ligand for SPECT. Ann Nucl Med 2021; 35: $167-175$.

12. Sahul ZH, Mukherjee R, Song J, McAteer J, Stroud RE, Dione $\mathrm{DP}$, et al. Targeted imaging of the spatial and temporal variation of matrix metalloproteinase activity in a porcine model of postinfarct remodeling: Relationship to myocardial dysfunction. Circ Cardiovasc Imaging 2011; 4: 381-391.

13. Branderhorst W, Vastenhouw B, Beekman FJ. Pixel-based subsets for rapid multi-pinhole SPECT reconstruction. Phys Med Biol 2010; 55: 2023-2034.

14. Miwa K, Inubushi M, Takeuchi Y, Katafuchi T, Koizumi M, Saga T, et al. Performance characteristics of a novel clustered multi-pinhole technology for simultaneous high-resolution SPECT/PET. Ann Nucl Med 2015; 29: 460-466.

15. Loening AM, Gambhir SS. AMIDE: A free software tool for multimodality medical image analysis. Mol Imaging 2003; 2: $131-137$.

16. Ela C, Barg J, Vogel Z, Hasin Y, Eilam Y. Sigma receptor ligands modulate contractility, $\mathrm{Ca}++$ influx and beating rate in cultured cardiac myocytes. J Pharmacol Exp Ther 1994; 269: $1300-1309$

17. Novakova M, Ela C, Barg J, Vogel Z, Hasin Y, Eilam Y. Inotropic action of sigma receptor ligands in isolated cardiac myocytes from adult rats. Eur J Pharmacol 1995; 286: 19-30.

18. Lewis R, Li J, McCormick PJ, Huang CLH, Jeevaratnam K. Is the sigma-1 receptor a potential pharmacological target for cardiac pathologies?: A systematic review. Int J Cardiol Heart Vasc 2019; 26: 100449 .

19. Zhou H, Wang S, Hu S, Chen Y, Ren J. ER-Mitochondria microdomains in cardiac ischemia-reperfusion injury: A fresh perspective. Front Physiol 2018; 9: 755.

20. Ruscher K, Shamloo M, Rickhag M, Ladunga I, Soriano L, Gisselsson L, et al. The sigma-1 receptor enhances brain plasticity and functional recovery after experimental stroke. Brain 2011; 134: $732-746$

21. Tarone G, Brancaccio M. Keep your heart in shape: Molecular chaperone networks for treating heart disease. Cardiovasc Res 2014; 102: $346-361$.

22. Wang S, Binder P, Fang Q, Wang Z, Xiao W, Liu W, et al. Endoplasmic reticulum stress in the heart: Insights into mechanisms and drug targets. Br J Pharmacol 2018; 175: 1293-1304.

23. Liu MQ, Chen Z, Chen LX. Endoplasmic reticulum stress: A novel mechanism and therapeutic target for cardiovascular diseases. Acta Pharmacol Sin 2016; 37: 425-443.

24. Bhuiyan MS, Tagashira H, Shioda N, Fukunaga K. Targeting sigma-1 receptor with fluvoxamine ameliorates pressure-overload-induced hypertrophy and dysfunctions. Expert Opin Ther Targets 2010; 14: 1009-1022. 